\title{
Reviews
}

\section{MOLECULAR GENETIC APPROACHES FOR INVESTIGATION OF TAXONOMY AND SPECIFIC IDENTIFICATION OF TOXIN- PRODUCING Fusarium SPECIES: ACHIEVEMENTS AND PROBLEMS}

(review)

\author{
A.A. STAKHEEV1, L.V. SAMOKHVALOVA', D.Yu. RYAZANTSEV1, S.K. ZAVRIEV1, 2 \\ ${ }^{1}$ M.M. Shemyakin and Yu.A. Ovchinnikov Institute of Bioorganic Chemistry, Federal Agency of Scientific Organizations, \\ 16/10, ul. Miklukho-Maklaya, Moscow, 117997 Russia, e-mail samokhlar@mail.ru, d.yu.ryazantsev@gmail.com, \\ stakheev.aa@gmail.com; \\ 2All-Russian Research Institute of Phytopathology, Federal Agency of Scientific Organizations, 5, ul. Institute, \\ pos. Bol'shie Vyazemy, Odintsovskii Region, Moscow Province, 143050 Russia, e-mail szavriev@ibch.ru \\ Acknowledgements: \\ Supported by Russian Foundation for Basic Research, project № 15-29-05902. \\ Received February 26, 2016
}

\section{Abstract}

Ascomycetous fungi of the genus Fusarium, which was separated as a single taxonomic group in 1809 by Heinrich Friedrich Link, are distributed worldwide and have different ecological niches. They have been found in soil and plants as endophytes, saprotrophs and parasites. Infections of agricultural plants, caused by Fusarium fungi, lead to annual damage, estimated in hundred million dollars. In addition to decrease harvest quality and quantity, Fusarium fungi are able to produce toxic metabolites (fusariotoxins). The consumption of fusariotoxin-contaminated winter grain led to deaths of tens of thousands of people in Volga and Ural regions in 1930s-1940s. These factors make necessary investigation of morphology, biochemistry and genetics of those organisms. Nowadays there is no universal taxonomic system of the genus Fusarium, so it is not possible to identify an isolate to species level in many cases. The high variability of morphological structures, and, on the other side, their similarity for closely related species, are major problems for researchers which use classical methods for identification and systematization of this group of fungi. Today, the molecular methods, based on the use of specific DNA sequence, are playing an increasingly important role in Fusarium systematics. The application of this approach has led to establishment of a number of new species in the genus. T. Yli-Mattila et al. $(2009,2011)$ used multilocus phylogenetic analysis to describe the novel species $F$. sibiricum and $F$. ussurianum which were found in Siberia and Far East and proved to be morphologically similar to $F$. graminearum and $F$. langsethiae, respectively. The authors of this paper identified the species $F$. torulosum (morphologically similar to $F$. avenaceum) in Russia for the first time based on the use of DNA markers. It is no less important that the analysis of interand intraspecific polymorphism makes possible the development of highly-specific assays for molecular detection of Fusarium fungi, including ones which infect plants and produce mycotoxins. The use of these assays (for example, ones described by M. Nicolaisen et al., 2009 and A.A. Stakheev et al., 2011) allows not only to detect the contamination of plants by mycotoxin producers, but also to estimate the quantity of their content in a probe. At the same time, a lot of questions are still unanswered: particularly, simultaneous application of different species concepts (morphological, biological and phylogenetic) makes it difficult to develop universal taxonomic system of the genus; also the most informative and reliable marker, which would reflect the evolutionary history of the genus, has not been found. The main achievements and problems of Fusarium phylogenetics, and perspectives of the application of molecular approach for studies of this group of organisms are discussed in this review.

Keywords: genus Fusarium, taxonomy, DNA marker, mycotoxins, phylogenetic analysis

The genus Fusarium was separated as a taxonomic group in 1809 by Heinrich Friedrich Link [1, 2]. Since then, many attempts to create a single universal system of the genus has been made, but they have not been successful to date. For a long time the genus Fusarium taxonomy was rather chaotic, and at a certain stage it included more than 1000 species. In many ways, this was due to the mistaken belief that each fungus species affects a single host plant species 
[3], so that each new isolate could be classified as a separate species. The number of Fusarium species in various taxonomic systems varied widely and ranged from 9 [4] to 78 [5], thereby demonstrating problems in classification of this group of organisms, which are largely due to the high morphological variability that impedes species-specific criteria and, as a result, makes the taxonomic status of many members of the genus Fusarium controversial [6]. In addition, the accumulating data further complicate the interpretation. For example, it was found that fusiform to sickle-shaped conidia that has been used by H.F. Link to separate Fusarium as a genus, could not be considered strictly typical for this group. Besides, it is revealed that the morphologically similar species can differ significantly on both the genetic and metabolic levels. To date it is apparent that the identification based solely on the comparison of morphological data, often is not quite correct. Last but not least, this is due to the so-called human factor, since not all researchers have the necessary skills and experience to deal with fungi. All these necessitate modern molecular methods to study taxonomy and diversity of Fusarium fungi, as well as new approaches for rapid and correct diagnosis of plant infection by these dangerous pathogens [3, 6].

To date, morphological, biological and phylogenetic species concepts are three main ones. Morphological concept is based on the description of shape and size of macroconidia, microconidia and chlamydospores, and the type of conidiogenous cells, with pigments and secondary metabolites also taken into consideration. Biological concept is based primarily on crossbreeding ability. As to the genus Fusarium, this approach is limited by the fact that a significant number of the representatives do not have a sexual stage in the life cycle and reproduce only asexually [7-9]. It should be noted that the biological concept, when applicable, allows for most accurate defying species boundaries due to unequivocal data on whether the strains can or can not mate with each other and produce fertile offspring [3, 10]. The study of complex species Gibberella fujikuroi (Fusarium fujikuroi as asexual stage), which included nine species identified is an example of the biological concept [11-13]. The basis of the phylogenetic species concept is a comparative analysis of the DNA nucleotide sequences that allows to find out the relationship of taxa and clarify their evolution [14]. The approaches used to study the genetic polymorphism of different taxonomic groups are based either on arbitrary DNA labeling, such as random amplified polymorphic DNA (RAPD) [15, 16], inter simple sequence repeats (ISSR) [17], and amplification fragments lengths polymorphism (AFLP) [18, 19] methods, or on polymorphism analysis based on sequence characterized amplified regions (SCAR) markers $[3,6,20]$. Among the significant disadvantages of the first approach are low reproducibility of the experimental results (particularly with respect to RAPD), and high DNA purity and concentration necessary to ensure accuracy. SCARmarkers are currently considered as the most reliable tools for genetic marking, which allow, in most cases, for unique identification of organismas by a characteristic sequence of one or more DNA loci. In phylogenetic approach the concept of cryptic species is often used, which is separated as a single taxon solely on the genetic differences [21, 22]. Genealogical concordance phylogenetic species recognition (GCPSR) is used to establish the boundaries of species in a multilocus phylogenetic analysis [23]. The most important task of the phylogenetic approach is to find a universal marker (DNA barcode) which 'would allow to characterize the taxonomic status of the representatives of a broad group of organisms [24]. Gene encoding subunit 1 of mitochondrial cytochrome Coxidase can be an example of the barcode for animal kingdom (Animalia Linnaeus, 1758). At the same time this marker is poorly applicable to the kingdom Fungi [Fungi (L., 1753) R.T. Moore, 1980], although it was used successfully for 
taxonomic studies of the genus Penicillium. Most researchers believe the internal transcribed spacers of ribosomal DNA (ITS) most phylogenetically informative marker for fungi [25]. However, some data shows that phylogenetic analysis of these loci does not always objectively reflects the evolution and taxonomic relationships among species for the genus Fusarium. One of the reasons is the fact that in many species (e.g., in Fusarium fujikuroi complex) the ITS2 spacer presents in two nonorthologous copies [3, 26]. Thus, the search for highly informative polymorphic markers that would uniquely identify the taxonomic status of the Fusarium genus remains an urgent task [27-29].

A significant number of reports on genetic polymorphism in Fusarium fungi with analysis of several genes encoding proteins and ribosomal RNA sequences have been published in the last 10-15 years. These are genes for $1 \alpha$ translation elongation factor $(t e f 1 \alpha)$ [30], $\beta$-tubulin $(\beta$-tub) [31], phosphate permease $(P H O)$ [32, 33], sterol 14-demethylase (CYP51C) [19], aminoadipate reductase (lys2) [20, 21], intergenic spacers (IGS) of rRNA genes [22], and a number of genes involved in cascade reactions of chemical synthesis. Due to high inter- and intraspecific polymorphism they can be successfully used in phylogenetic studies of the genus. Currently, the tefl $\alpha$ gene, which is the most similar to the DNA barcode is considered the most informative loci for phylogenetic analysis of the genus Fusarium. A database FUSARIUM-ID v. 1.0 [23] composed of nucleotide sequence of the tefl $\alpha$ gene fragments in many cases contributes to faster and easier identification of unknown strains. However, incomplete sequences for some species in the database, and not always correct initial identification of strains lead to a confusion when associating the sequence with a particular species.

Certain difficulties in multilocus phylogenetic analysis are due to differences in the evolutionary history of different genes. An example is phosphate permease gene $(\mathrm{PHO})$, which was used for the taxonomic studies of several groups of Fusarium pathogens. Thus, J.B. Scott and S. Chakraborty [40] have successfully used it as a marker to classify $F$. pseudograminearum as a separate species. Later $\mathrm{PHO}$ gene was used in four-locus phylogeny analysis [33] which allows to distinguish a number of isolates from Siberia and the Far East, originally identified as $F$. poae, as a separate species $F$. sibiricum. At the same time PHO gene is polymorphic enough to clearly distinguish $F$. culmorum from the closely related $F$. cerealis [41]. We used $P H O$ as a marker for intra- and interspecific polymorphism study in $F$. avenaceum, $F$. tricinctum, $F$. acuminatum, $F$. torulosum, producing toxins of enniatin group and moniliformin [32]. It has been shown that for this group of species $\mathrm{PHO}$ has a higher variability than the «classical» markers such as tefl $\alpha, \beta$-tub, or enniatin synthetase (Esyn 1) genes. Phylogenetic analysis of $F$. avenaceum strains from different regions of Russia using the $\mathrm{PHO}$ gene sequences showed four of them to form an independent cluster phylogenetically closer to $F$. torulosum, than to $F$. avenaceum, which is conventionally called $F$. avenaceum-V. Perhaps this group of strains can be treated as a separate phylogenetic species, but this fact has not been confirmed in the analysis of other markers and requires further study. At the same time, we have not found a correlation between the phylogeny of the strains and their division into conventional groups I and II proposed by T. Yli-Mattila et al. [31, 38]. Moreover, these markers did not allow to identify $F$. arthrosporioides strain as a separate taxa other than $F$. avenaceum, thereby confirming the hypothesis that $F$. arthrosporioides is not a separate species. Amino adipate reductase gene (lys2) is another example of a different evolutionary history. The lys 2 gene has been shown to be phylogenetically more informative than the number of traditional markers, but the topology of the phylogenetic tree constructed on the basis of comparative 
analysis of lys 2 sequences differed significantly from that obtained from other genes [35, 36]. A possible solution is to use a multilocus analysis for several genes to smooth down the possible differences in the evolution and polymorphism of the loci and get a picture as close to the objective as possible [42, 43].

Despite all the difficulties, the use of molecular markers have significantly contributed to biology and taxonomy of Fusarium fungi. New taxonomic groups revealed within the genus, such as $F$. sibiricum, $F$. pseudograminearum, and $F$. ussurianum [44], are the examples. Furthermore, DNA-markers allowed distinguishing nine phylogenetic species in $F$. graminearum [45]. Due to tefl $\alpha$ gene sequence phylogenetic analysis, northern European and southern European groupes have been clustered within $F$. equiseti [46]. Also new taxonomic groups have been found in the $F$. fujikuroi and $F$. solani complexes [3].

Due to study of genetic polymorphism in the Russian population of Fusarium pathogens and development of the appropriate markers we have identified the species $F$. torulosum, morphologically similar to $F$. avenaceum, in Russia for the first time [47]. Also species identification was verified for Fusarium strains from the Russian National Collections, including All-Russian Collection of Microorganisms (G.K. Skryabin Institute of Biochemistry and Physiology of Microorganisms RAS, Pushchino), Collection of All-Russian Institute of Plant Protection (St. Petersburg) and Collection of All-Russian Research Institute of Phytopathology (Moscow Province). Molecular approach made it possible to evaluate the relationship between species, which was non-obvious when comparing morphological features. An example is $F$. tricinctum, traditionally regarded as a closely related to $F$. sporotrichioides and $F$. poae species and attributable to Sporotrichiella section [48-50]. However, F. tricinctum can produce enniatins and moniliformin, the toxic metabolites, that distinguishes it from $F$. sporotrichioides and $F$. poae, secreting mainly trichothecene mycotoxins. On this criterion $F$. tricinctus is close to F. avenaceum and F. acuminatum, attributable to Roseum and Gibbosum sections, respectively [51]. Phylogenetic analysis from multiple genes confirmed the close relationship between $F$. tricinctum, $F$. avenaceum and $F$. acuminatum.

The figure shows a dendrogram based on the phylogeny analysis of tefl $\alpha$ gene sequenced and described by the authors of this article for 14 Fusarium species from the Russian National Collection, and those deposited in GenBank NCBI (accession numbers listed in the Table). Noteworthy, the species are clustered in strict accordance with their mycotoxin patterns, i.e. A trichothecenes producers ( $F$. sporotrichioides, $F$. langsethiae), B trichothecenes producers ( $F$. graminearum, $F$. culmorum, $F$. cerealis, and those predominantly synthetizing B trichothecenes, such as $F$. poae, $F$. venenatum, $F$. sambucinum), and enniatins and moniliformin producers ( $F$. avenaceum, $F$. tricinctum, $F$. acuminatum, $F$. torulosum).

Fusarium strains from the Russian National Collection used in phylogenetic studies

\begin{tabular}{|c|c|c|c|}
\hline Strain & Species & Origin & Host plant \\
\hline $96800^{1}$ & F. acuminatum & North Ossetia & Wheat \\
\hline CM-9866 2 & F. avenaceum & Smolensk Province & Wheat \\
\hline $64722^{1}$ & F. cerealis & Хабаровский край & Wheat \\
\hline $74007^{1}$ & F. culmorum & Arkhangelsk Province & Potato \\
\hline $97001^{1}$ & $F$. equiseti & North Ossetia & Wheat \\
\hline $58033^{1}$ & F. graminearum & Leningradskaya Province & Barley \\
\hline $82901^{1}$ & $F$. langsethiae & Orel Province & Oats \\
\hline $61701^{1}$ & F. poae & Saratov Province & Wheat \\
\hline $\mathrm{F}-842^{3}$ & F. sambucinum & Bekaya Tserkov', Ukraine & Potato \\
\hline $\mathrm{HTiMi}^{2}$ & F. solani & Unknown & Unknown \\
\hline BR-04-602 & F. sporotrichioides & Bryansk Province & Wheat \\
\hline $90604^{1}$ & F. torulosum & Leningradskaya Province & Barley \\
\hline $30141^{1}$ & F. tricinctum & Finland & Barley \\
\hline $58242^{1}$ & F. venenatum & Germany & Unknown \\
\hline \multicolumn{4}{|c|}{$\begin{array}{l}\text { N o t e. 1, } 2 \text { and } 3-\text { collections of All-Russian Institute of Plant Protection (St. Petersburg), of All-Russian Re- } \\
\text { search Institute of Phytopathology (Moscow Province) and All-Russian Collection of Microorganisms (G.K. Skryabin } \\
\text { Institute of Biochemistry and Physiology of Microorganisms RAS, Pushchino), respectively. }\end{array}$} \\
\hline
\end{tabular}




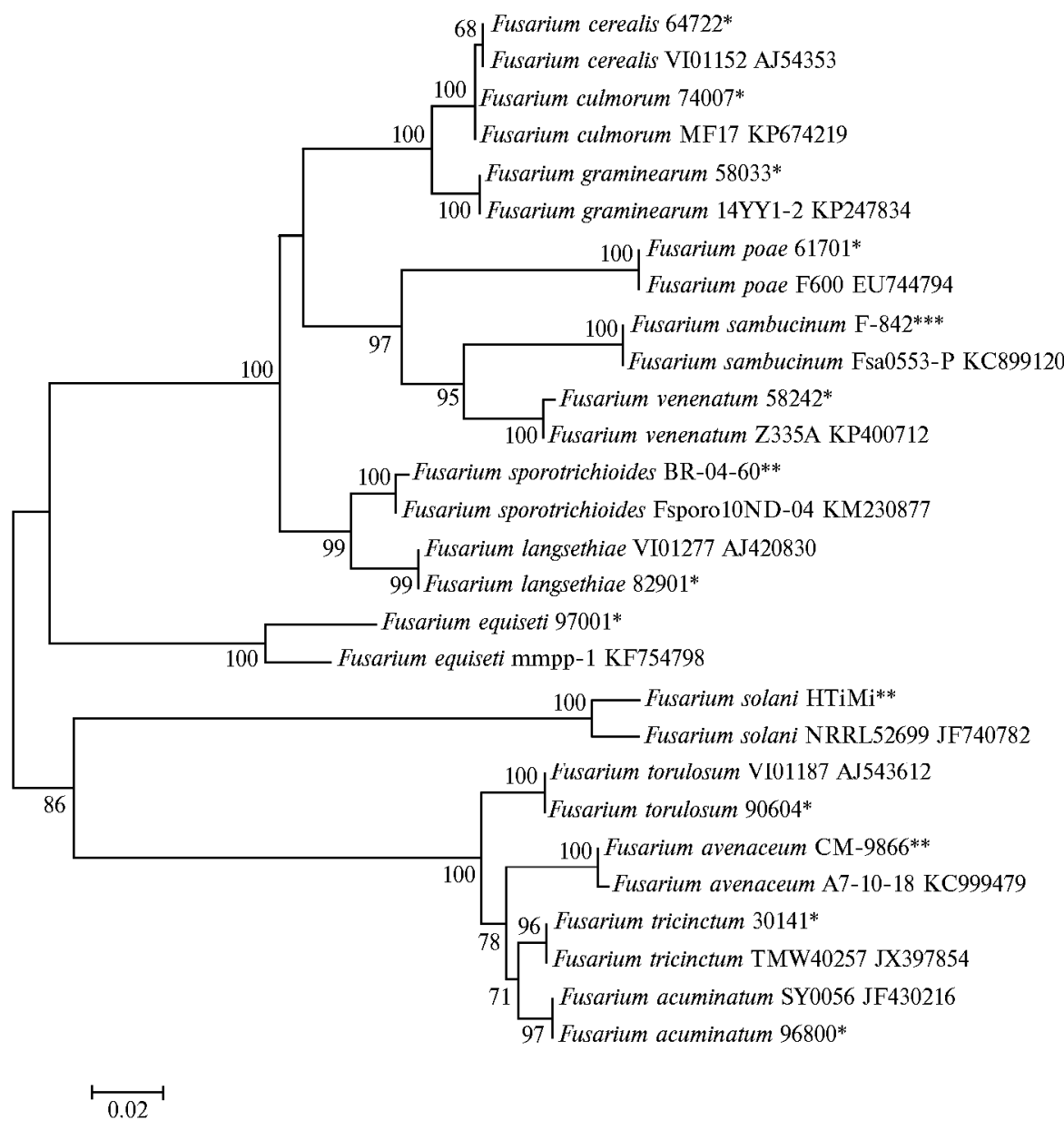

Dendrogram based on tef1 $\alpha$ sequences for 14 Russian Fusarium strains from the Russian National Collection and those deposited in GenBank (NCBI). Neighbor joining algorithm (MEGA5) applied, with bootstrap support over $50 \%$. For deposited sequences the accession numbers are indicated. One, two and three asterisks mark strains from Collection of All-Russian Institute of Plant Protection (St. Petersburg), Collection of All-Russian Research Institute of Phytopathology (Moscow Province) and All-Russian Collection of Microorganisms (G.K. Skryabin Institute of Biochemistry and Physiology of Microorganisms RAS, Pushchino), respectively.

Data on interspecies polymorphism of specific DNA loci facilitates the development highly specific detection system for Fusarium pathogens based on classical PCR or its modification [52-61]. Routine application of these systems provides rapid and accurate identification of a pathogen at different levels (species, subspecies or species groups depending on the task), and hence allows to predict the potentially accumulated mycotoxins. RT-PCR [62] allows to determine the pathogen DNA amounts, thereby tracking the infection development and the fungicide effectiveness, and also to carry out regular monitoring of the Fusarium infestation (e.g., in grain and by-products). L. Niessen et al. [63] suggested a good alternative to PCR. They used a loop-mediated isothermal amplification (LAMP) method to detect $F$. tricinctum in pure cultures and grain [64]. Its sensitivity is comparable to that of the classical PCR (0.95 pg of target DNA per reaction), but cross-reactions were observed with the DNA of $F$. acuminatum strains, that is, this method was not completely specific. Nevertheless, it may be promising compared to the PCR as does not require sophisticated and expensive equipment.

So, despite challenges, molecular genetic approaches have good pro- 
spects and potential for solving problems in the taxonomy of the genus Fusarium. Nevertheless, these techniques should not be considered «means of escape» from the difficulties in Fusarium classification. Phylogenetic methods used without studying morphology, strain crossbreeding and metabolism can only complicate the problem. Only relevant combination of several approaches will provide valid and reliable data on the basis of which a relatively universal taxonomic system can be created to satisfy professionals in one way or another involved in studying this group of plant pathogens.

\section{REFEREN C ES}

1. N e 1 s o n P.E. History of Fusarium systematics. Phytopathology, 1991, 81(9): 1045-1048.

2. Nelson P.E., Dignani M.C., Anaissie E.J. Taxonomy, biology, and clinical aspects of Fusarium species. Clin. Microbiol. Rev., 1994, 7(4): 479-504 (doi: 10.1128/CMR.7.4.479).

3. L e s 1 i e J.F., S u m m e re 11 B.A. The Fusarium laboratory manual. Blackwell Publishing, 2006.

4. S n yde r W.C., H a n se n H.N. Variation and speciation in the genus Fusarium. Annals of the New York Academy of Sciences, 1954, 60: 16-23.

5. G e rla ch W. The present concept of Fusarium classification. Pennsylvania State University Press, 1981 .

6. Gagkaeva T.Yu., Gavrilova O.P., Levitin M.M., Novozhilov K.V. Zashchita $i$ karantin rastenii, 2011, 5: 69-120 (in Russ.).

7. Dobzhnsky T. Mendelian populations and their evolution. American Naturalist, 1950, 84(9): 401-418.

8. M a y E. Animal species and evolution. Harvard University Press, 1963.

9. Britz H., Coutinho T.A., Wingfield M.J., Marasas W.F.O., Gordon T.R., Leslie J.F. Fusarium subglutinans f. sp. pini represents a distinct mating population in the Gibberella fujikuroi species complex. Appl. Environ. Microbiol., 1999, 65(3): 1198-1201.

10. Proctor R.H., B rown D.W. Fusarium: genomics, molecular and cellular biology. Caister Academic Press, 2013.

11. L e s li e J.F. Mating populations in Gibberella fujikuroi. Phytopathology, 1991, 81: 1058-1060.

12. L e sli e J.F. Gibberella fujikuroi: available populations and variable traits. Can. J. Bot., 1995, 73(Suppl. 1): S282-S291 (doi: 10.1139/b95-258).

13. Les 1 i e J.F. Genetic status of the Gibberella fujikuroi species complex. Plant Pathol. J., 1999, 15: 259-269.

14. Harringto n T.C., Rizzo D.M. Defining species in the fungi. In: Structure and dynamics of fungal populations. J.J. Worrall (ed.). Kluwer Academic Publishers, 1999.

15. S t a kh e ev A.A., Ry a $\mathrm{z}$ a $\mathrm{t} \mathrm{sev}$ D.Yu., Z a v ri e v S.K. Bioorganicheskaya khimiya, 2011, 37(5): 662-671 (doi: 10.1134/S1068162011050189) (in Russ.).

16. Turner A.S., Lees A.K., Rezanoor H.N., Nicholson P. Refinement of PCRdetection of Fusarium avenaceum and evidence from DNA marker studies for phonetic relatedness to Fusarium tricinctum. Plant Pathol., 1998, 47: 278-288 (doi: 10.1046/j.1365-3059.1998.00250.x).

17. Nirmaladevi D., Venkataramana M., S rivastava R.K., Uppalapati S.R., Gupta V.K., Yli-Mattila T., Tsui K.M.C., Srinivas C., Niranjana S.R., $\mathrm{C} \mathrm{h}$ a nd r a N.S. Molecular phylogeny, pathogenicity and toxigenicity of Fusarium oxysporum $\mathrm{f}$. sp. lycopersici. Sci. Rep., 2016, 6: 21367 (doi: 10.1038/srep21367).

18. Jurgenson J.E., Bowden R.L., Zeller K.A., Leslie J.F., Alexander N.J., Plattne r R.D. A genetic map of Gibberella zeae (Fusarium graminearum). Genetics, 2002, 160: 1452-1460.

19. Z e 11 e r K.A., B ow d e n R.L., L e s li e J.F. Diversity of epidemic populations of Gibberella zeae from small quadrats in Kansas and North Dakota. Phytopathology, 2003, 93: 874-880 (doi: 10.1094/PHYTO.2003.93.7.874).

20. Paran I., Michelmore R.W. Development of reliable PCR-based markers linked to downy mildew resistance genes in lettuce. Theor. Appl. Genet., 1993, 85: 985-993 (doi: 10.1007/BF00215038).

21. Crespo A., Lumbsch H.T. Cryptic species in lichen-forming fungi. IMA Fungus, 2010, 1(2): 167-170.

22. Taylor J.W., Turner E., Pringle A. Fungal species: thoughts on their recognition, maintenance and selection. In: Fungi in the environment. G.M. Gadd, S.C. Watkinson, P.S. Dyer (eds.). Cambridge University Press, 2007.

23. Taylor J.W., Jacobson D.J., Kroken S., Kasuga T., Geiser D.M., Hibbert D.S., $\mathrm{F}$ is h e r M.C. Phylogenetic species recognition and species concepts in fungi. Fung. Genet. Biol., 2000, 31: 21-32 (doi: 10.1006/fgbi.2000.1228).

24. S h n e e r V.S. Zhurnal obshchei biologii, 2009, 70(4): 296-315 (in Russ.).

25. Schoch C.L., Seifert K.A., Huhndorf S., Robert V., Spouge J.L., Levesque C.A., Che n W., Fungal Barcoding Consortium. Nuclear ribosomal internal transcribed 
spacer (ITS) region as a universal DNA barcode marker for Fungi. PNAS, 2012, 109: 6241-6246 (doi: 10.1073/pnas.1117018109).

26. Harrow S.A., Farrokhi-N ejad R., Pit man A.R., S cott I.A.W., B e n t ley A., Hid e C., C ro m e y M.G. Characterization of New Zealand Fusarium populations using a polyphasic approach differentiates the $F$. avenaceum/F.acuminatum/F.tricinctum species complex in cereal and grassland systems. Fungal Biology, 2010, 114: 293-311 (doi: 10.1016/j.funbio.2010.01.005).

27. Ge ise r D.M., Klich M.A., Frisvad J.C., Peterson S.W., Varga J., S a ms o n R.A. The current status of the species recognition and identification in Aspergillus. Stud. Mycol., 2007, 59: 1-10 (doi: 10.3114/sim.2007.59.01).

28. Seifert K.A., Samson R.A., deWaard J.R. Prospects for fungus identification using CO1 DNA barcodes, with Penicillium as a test case. PNAS USA, 2007, 104: 3901-3906 (doi: 10.1073/pnas.0611691104).

29. Aveskamp M.M., de Gruyter J., Woudenberg J.H.C. Highlights of the Didymellace$a e$ : a polyphasic approach to characterize Phoma and related pleosporalean genera. Stud. Mycol., 2010, 65: 1-60 (doi: 10.3114/sim.2010.65.01).

30. Kristensen R., Torp M., Kosiak B., Holst-Jensen A. Phylogeny and toxigenic potential is correlated in Fusarium species as revealed by partial translation elongation factor 1 alpha gene sequences. Mycol. Res., 2005, 109: 173-186 (doi: 10.1017/S0953756204002114).

31. Yli-Mattila T., Pa avanen-Huhtala S., Bulat S.A., Alekhina I.A., Ni re nberg H.I. Molecular, morphological and phylogenetic analysis of the Fusarium avenaceum $/ F$. arthrosporioides $/ F$. tricinctum species complex - a polyphasic approach. Mycol. Res., 2002, 106(6): 655-669 (doi: 10.1017/S0953756202006020).

32. S t a k h e e v A.A., K ha i rulina D.R., Z a v ri e v S.K. Four-locus phylogeny of Fusarium avenaceum and related species and their species-specific identification based on partial phosphate permease gene sequences. Int. J. Food Microbiol., 2016, 225: $25-37$ (doi: 10.1016/j.ijfoodmicro.2016.02.012).

33. Yli-Mattila T., Ward T.J., O'Donnell K., Proctor R.H., Burkin A.A., Kononenko G.P., Gavrilova O.P., Aoki T., Mc Cormick S.P., Gagkaeva T.Y. Fusarium sibiricum sp. nov, a novel type A trichothecene-producing Fusarium from northern Asia closely related to F. sporotrichioides and F. langsethiae. Int. J. Food Microbiol., 2011, 147: 58-68 (doi: 10.1016/j.ijfoodmicro.2011.03.007).

34. Fernández-Ortuco D., Loza-Reyes E., Atkins S.L., Fraaije B.A. The CYP51C gene, a reliable marker to resolve interspecific phylogenetic relationships within the Fusarium species complex and a novel target for species-specific PCR. Int. J. Food Microbiol., 2010, 144: 301-309 (doi: 10.1016/j.ijfoodmicro.2010.10.013).

35. Watanabe M., Yonezava T., Lee K-I., Kumagai S., Sugita-Konishi Y., Goto K., Hara-Kudo Y. Evaluation of genetic markers for identifying isolates of the species of the genus Fusarium. J. Sci. Food Agr., 2011, 91: 2500-2504 (doi: 10.1002/jsfa.4507).

36. Watanabe M., Yonezava T., Lee K-I., Kumagai S., Sugita-Konishi Y., Goto K., Hara-Kudo Y. Molecular phylogeny of the higher and lower taxonomy of the Fusarium genus and differences in the evolutionary histories of multiple genes. BMC Evol. Biol., 2011, 11: 322 (doi: 10.1186/1471-2148-11-322).

37. Llorens A., Hinojo M.J., Mateo R., Gonsales-Jaen M.T., Valle-Algarra F.M., Logriecco A., Jimenez M. Characterization of Fusarium spp. isolates by PCR-RFLP analysis of the rRNA gene (rDNA). Int. J. Food Microbiol., 2006, 106: 297-306 (doi: 10.1016/j.ijfoodmicro.2005.09.005).

38. Yli-Mattila T., Paavanen-Huhtala S., Parikka P., Konstantinova P., Gagk a v a T.Y. Molecular and morphological diversity of Fusarium species in Finland and north-western Russia. Eur. J. Plant Pathol., 2004, 110: 573-585 (doi: 10.1023/B:EJPP.0000032397.65710.69).

39. Geiser D.M., Jimenes-Gasco M., Kang S., Makalowska I., Veeraraghavan N., Ward T.J., Zhang N., Kuldau G.A., O'Donnell K. FUSARIUM-ID v. 1.0: A DNA sequence database for identifying Fusarium. Eur. J. Plant Pathol., 2004, 110: 473-479 (doi: 10.1023/B:EJPP.0000032386.75915.a0).

40. Scott J.B., Chakraborty S. Multilocus sequence analysis of Fusarium pseudograminearum reveals a single phylogenetic species. Mycol. Res., 2006, 110: 14131425 (doi: 10.1016/j.mycres.2006.09.008).

41. Obanor F., Erginbas-Orakci G., Tunali B., Nicol J.M., Chakraborty S. Fusarium culmorum is a single phylogenetic species based on multilocus sequence analysis. Fungal Biol., 2010, 114: 753-765 (doi: 10.1016/j.funbio.2010.07.001).

42. Kulik T., Pszczolkowska A., Lojko M. Multilocus phylogenetics show high intraspecific variability within Fusarium avenaceum. Int. J. Mol. Sci., 2011, 12: 5626-5640 (doi: 10.3390/ijms12095626).

43. O'Donnell K., Sutton D.A., Rinaldi M.G., Gueidan C., Crous P.W., Geise r D.M. Novel multilocus sequence typing scheme reveals high genetic diversity of human pathogenic members of the Fusarium incarnatum- $F$. equiseti and $F$. chlamydosporum species complexes within the United States. J. Clin. Microbiol., 2009, 47: 3851-3861 (doi: 10.1128/JCM.01616-09). 
44. Yli-Mattila T., Gagkaeva T., Ward T.J., Aoki T., Kistler H.C., O'Donnell K. A novel Asian clade within the Fusarium graminearum species complex includes a newly discovered cereal head blight pathogen from Russian Far East. Mycologia, 2009, 101(6): 841-852 (doi: 10.3852/08-217).

45. O'Donnell K., Ward T.J., Geiser D.M., Kistler H.C., Aoki T. Genealogical concordance between the mating type locus and seven other nuclear genes supports formal recognition of nine phylogenetically distinct species within the Fusarium graminearum clade. Fungal Genet. Biol., 2004, 41: 600-623 (doi: 10.1016/j.fgb.2004.03.003).

46. Marín P., Moretti A., Ritieni A., Jurado M., Vázquez C., Gonzalez Ja é n M.T. Phylogenetic analyses and toxigenic profiles of Fusarium equiseti and Fusarium acuminatum from cereals from Southern Europe. Food Microbiol., 2012, 31: 229-237 (doi: 10.1016/j.fm.2012.03.014).

47. Gagkaeva T.Yu., Gavrilova O.P., Stakheev A.A., Ryazantsev D.Yu., Zavrie v S.K. Mikologiya i fitopatologiya, 2012, 46: 86-91 (in Russ.).

48. B o oth C. The genus Fusarium. Commonwealth Mycological Institute, 1971.

49. Gerlach W., Nirenberg H.I. The genus Fusarium - a pictorial atlas. Mitt. Biol. Bundesanst Land-u Forstwirsch Berlin-Dahlem, 1982.

50. Nelson P.E., Tous ou n T.A., Marasas W.F.O. Fusarium species: an illustrated manual for identification. Pennsylvania State University Press, 1983.

51. Jestoi M. Emerging Fusarium mycotoxins fusaproliferin, beauvericin, enniatins, and moniliformin - a review. Critical Reviews in Food Science and Nutrition, 2008, 48: 21-49 (doi: $10.1080 / 10408390601062021)$

52. Fernández-Ortuco D., Waalwijk C., Van der Lee T., Fan J., Atkins S., West J.S., Fraaije B.A. Simultaneous real-time PCR detection of Fusarium asiaticum, $F$. ussurianum and $F$. vorosii, representing the Asian clade of the $F$. graminearum species complex. Int. J. Food Microbiol., 2013, 166: 148-154 (doi: 10.1016/j.ijfoodmicro.2013.06.007).

53. Fredlund E., Gidlund A., Sulyok M., Börjesson T., Krska R., Olsen M., Lindblad M. Deoxynivalenol and other selected Fusarium toxins in Swedish oats - occurrence and correlation to specific Fusarium species. Int. J. Food Microbiol., 2013, 167: 276-283 (doi: 10.1016/j.ijfoodmicro.2013.06.026).

54. Jurado M., Vazquez C., Marin S., Sanchis V., Tereza Ganzalez-Jaen M. PCR-based strategy to detect contamination with mycotoxigenic Fusarium species in maize. Syst. Appl. Microbiol., 2006, 29: 681-689 (doi: 10.1016/j.syapm.2006.01.014).

55. Kulik T. Detection of Fusarium tricinctum from cereal grain using PCR assay. J. Appl. Genet., 2008, 49: 305-311 (doi: 10.1007/BF03195628).

56. Kulik T., J estoi M. Quantification of Fusarium poae DNA and associated mycotoxins in asymptomatically contaminated wheat. Int. J. Food Microbiol., 2009, 130: 233-237 (doi: 10.1016/j.ijfoodmicro.2009.01.036).

57. Nicolaisen M., Suproniene S., Nielsen L.K., Lazzaro I., Spliid N.H., Justes e n A.F. Real-time PCR for quantification of eleven individual Fusarium species in cereals. J. Microbiol. Meth., 2009, 76: 234-240 (doi: 10.1016/j.mimet.2008.10.016).

58. Niessen M.L., Vogel R.F. Group-specific PCR detection of potential trichotheceneproducing Fusarium species in pure cultures and cereal samples. Syst. Appl. Microbiol., 1998, 21: 618-631 (doi: 10.1016/S0723-2020(98)80075-1).

59. Stakheev A.A., Ryazantsev D.Yu., Gagkaeva T.Yu., Zavriev S.K. PCR detection of Fusarium fungi with similar profiles of the produced mycotoxins. Food Control, 2011, 22: 462-468 (doi: 10.1016/j.foodcont.2010.09.028).

60. Yli-Mattila T., Paavanen-Huhtala S., Parikka P., Jestoi M., Klemsdal S.S., R i z z o A. Genetic variation, real-time PCR, metabolites and mycotoxins of Fusarium avenaceum and related species. Mycotoxin Res., 2006, 2: 79-86 (doi: 10.1007/BF02956768).

61. Ryazantsev D.Yu., Abramova S.L., Evstratova S.V., Gagkaeva T.Yu., Zavriev S.K.. Bioorganicheskaya khimiya, 2008, 34(6): 799-807 (doi: 10.1134/S1068162008060113) (in Russ.).

62. Bustin S.A., Benes V., Garson J.A., Hellemans J., Huggett J., Kubista M., Mueller R., Nolan T., Pfaffl M.W., Shipley G.L., Vandesompele J., Wittwe r C.T. The MIQE guidelines: minimum information for publication of quantitative realtime PCR experiments. Clin. Chem., 2009, 55: 611-622 (doi: 10.1373/clinchem.2008.112797).

63. $\mathrm{N}$ i e s s e $\mathrm{n}$ L., $\mathrm{G}$ raf e $\mathrm{nh}$ a $\mathrm{n}$ T., Voge 1 R.F. ATP citrate lyase 1 (acl1) gene-based loop-mediated amplification assay for the detection of the Fusarium tricinctum species complex in pure cultures and in cereal samples. Int. J. Food Microbiol., 2012, 158: 171185 (doi: 10.1016/j.ijfoodmicro.2012.06.021).

64. Notomi T., Okayama H., Masubuchi H., Yonekawa T., Watanabe K., Amino N., H a s e T. Loop-mediated isothermal amplification of DNA. Nucleic Acids Res., 2000, 28: e63. 